\title{
Effects of Pre-Strain on the Evolution of Microstructure and Strain Hardening of Extruded Az31 Magnesium Alloy
}

\author{
Lifei Wang ${ }^{a, b, c, *}$, Miao Cao ${ }^{a}$, Shuming Yang ${ }^{d}$, Hua Zhang ${ }^{a, b, c}$, Dongya Wang ${ }^{c}$, Xiaoqing Cao ${ }^{a}$ \\ a Shanxi ley laboratory of advanced magnesium-based materials, Taiyuan 030024, China \\ ${ }^{b}$ Key Laboratory of Interface Science and Engineering in Advanced Materials, Ministry of Education, \\ Taiyuan University of Technology, Taiyuan 030024, China \\ ${ }^{c}$ College of Materials Science and Engineering, Taiyuan University of Technology, Taiyuan 030024, China \\ ${ }^{d}$ College of basic education, National University of defense technology, Changsha 410072, China
}

Received: July 02, 2016; Accepted: May 02, 2017

\begin{abstract}
Pre-compression $3 \%$ and pre-stretch $3 \%$ subsequent annealing at $200^{\circ} \mathrm{C}$ for $2 \mathrm{~h}$ are conducted on AZ31 magnesium alloys, then inverse tensile and compressive deformation are carried out at room temperature, respectively. During inverse tension 3\% deformation on $1^{\text {st }}$ pre-compression samples, detwinning behavior happens; after $2^{\text {nd }}$ pre-compression $3 \%$, the volume fraction of $\{10-12\}$ extension twins decreases comparing with $1^{\text {st }}$ pre-compression. Due to the interaction of dislocation and induced twinning lamellas, strain hardening rate $(\theta)$ increases on $1^{\text {st }}$ and $2^{\text {nd }}$ pre-compression samples. $\{10-12\}$ tensile twinning is restrained during inverse compressive deformation by pre-stretch process. Owing to the decreasing amount of twins, the texture strengthening in compressive deformation weakens. So the slop of stage III in strain hardening rate sustaining reduces after $1^{\text {st }}$ pre-stretch $3 \%$ and $2^{\text {nd }}$ prestretch 3\% deformation during inverse compression deformation.
\end{abstract}

Keywords: AZ31 magnesium alloy, microstructure, pre-strain, strain hardening

\section{Introduction}

Due to advantages of high specific strength, low density and so on, magnesium alloys have been attracted by a large number of industrial sectors ${ }^{1,2}$. However, the basal plane only provides two independent slipping systems owing to its hexagonal close packed (HCP) structure which cannot fit Von-Misses criterion with five slipping systems ${ }^{3,4}$. At this time, twinning plays an important role to coordinate the deformation. Twinning is a polar deformation mechanism which is active only when the load is on specific direction of $\mathrm{c}$-axis of Mg grains (compression perpendicular to c-axis or tension parallel to c-axis $)^{5,6}$. Currently, the effects of pre-twinning induced by pre-strain on the properties of magnesium alloys are widely investigated.

Song et al. ${ }^{7}$ cold pre-rolled on AZ31 magnesium plates along transverse direction for a small thickness reduction, the strength improved and yield asymmetry was weakened. $\mathrm{Xu}$ et al. ${ }^{8}$ conducted multidirectional pre-compression along three directions of magnesium blocks, the tension-compression asymmetry reduced. Lou et al. ${ }^{9}$ carried out dynamic plastic pre-deformation along the rolling direction at a smaller degree, the ductility improved largely. Ozaki et al. ${ }^{10}$ indicated that pre-compression along extrusion direction to induce $\{10$ $12\}$ extension twins, fatigue life of magnesium alloys got improved due to twinning-detwinning behavior during

* e-mail: wanglifei@tyut.edu.cn cycling deformation. Xin et al. ${ }^{11}$ reported that maximum thickness reduction per pass of $\mathrm{Mg}$ alloys sheet during rolling at $300{ }^{\circ} \mathrm{C}$ increased after pre-extension twinning. While, Zhang et al. ${ }^{12}$ pre-stretched on $\mathrm{Mg}$ alloy sheet and subsequent annealing, the formability enhanced greatly after pre-strain process. Besides, pre-strain plays also an important role on the strain hardening of magnesium alloys. Sarker et al. ${ }^{13}$ indicated the strain hardening rate of AM30 magnesium alloys increased with a positive slope after pre-compression along extrusion direction to induce $\{10-12\}$ extension twinning during stage B. Wu et al. ${ }^{14}$ introduced the excess twinned grains through pre-compression along the rolling direction, the rapid strain hardening reduced after the pre-twinning process.

Thus, pre-strain can be regarded as an effective way to modify the microstructures and properties (strength ${ }^{7}$, yield asymmetry $^{8}$, ductility ${ }^{9}$, fatigue life $^{10}$, and formability ${ }^{11,12}$ et al.) of Mg alloys. Besides, it has an important effect on the strain hardening during deformation ${ }^{13,14}$. About the strain hardening, pre-compression process is mainly focused; however, the effects of pre-stretch have rarely investigated. While it is much more significant to make clear how the pre-strain affects the strain hardening behavior, no matter pre-compression but also pre-stretch, especially during cycling deformation. Therefore, the effects of pre-compression and pre-stretch on the evolution of microstructure and strain hardening of $\mathrm{Mg}$ alloys have been systemic studied in this paper. 


\section{Experimental Procedure}

As-extruded AZ31 magnesium bars with a diameter of $16 \mathrm{~mm}$ are used as the initial materials. And a diameter and length with $12 \mathrm{~mm} \times 100 \mathrm{~mm}$ billets are cut from the bars for pre-strain process. Firstly, the billets are $1^{\text {st }}$ pre-compression by $3 \%$ along extrusion direction (ED). While subsequent annealing process is carried out at $200^{\circ} \mathrm{C}$ for $2 \mathrm{~h}$ to remove the dislocations. After that, reversed tension 3\% is conducted. Then $2^{\text {nd }}$ pre-compression is taken again for $3 \%$ degree. At last, the tensile samples are wire-cutting from as-received, $1^{\text {st }}$ pre-compression and $2^{\text {nd }}$ pre-compression billets to tensile fracture. The dimensions of tensile specimens are with nominal gage of $6 \mathrm{~mm} \times 36 \mathrm{~mm}$. In order to avoid bending-buckling of $\mathrm{Mg}$ billet during pre-compression, a special die is used to hold the samples, as shown in section view Figure 1. Two separate holders are used to provide side stress during so as to prevent lateral strain.

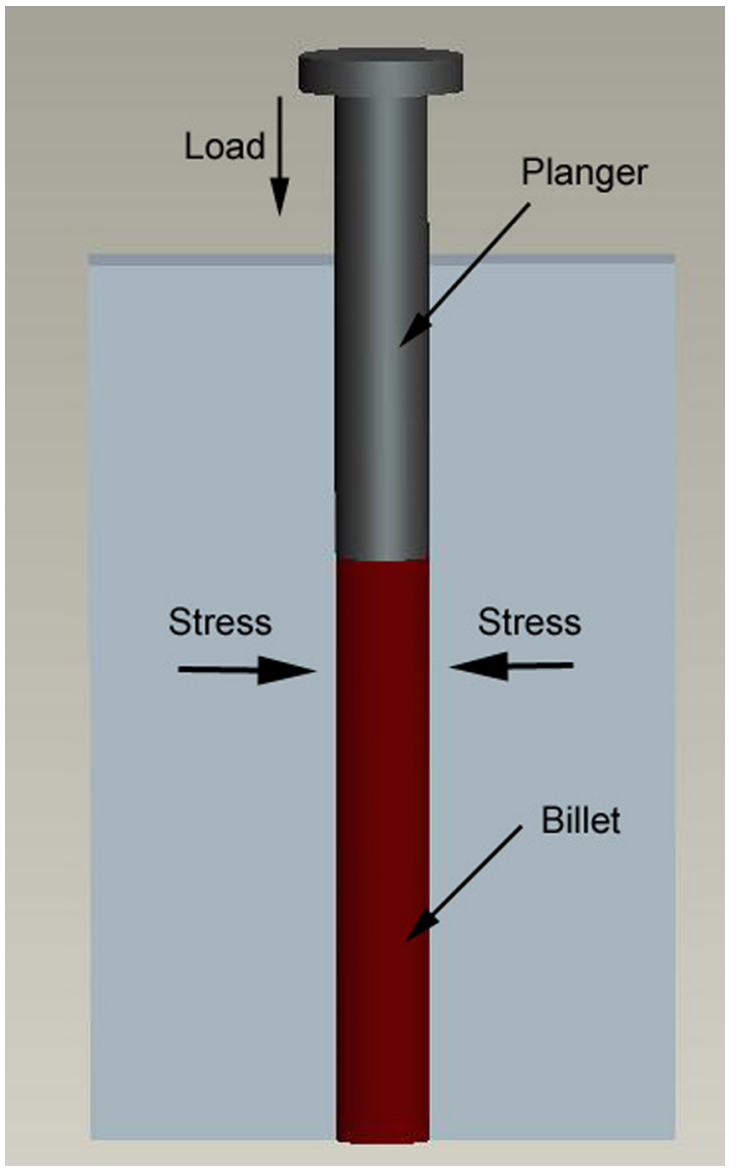

Figure 1. The section view of pre-compression die on $\mathrm{Mg}$ alloy billets

The same dimensions with $12 \mathrm{~mm} \times 100 \mathrm{~mm}$ billets are used for pre-stretch process. Firstly, the billets are $1^{\text {st }}$ pre-stretch $3 \%$ along ED. After annealing at $200^{\circ} \mathrm{C}$ for $2 \mathrm{~h}$, pre-compression $3 \%$ is taken out. Then $2^{\text {nd }}$ pre-stretch $3 \%$ is conducted. At the end, the compressed specimens are taken from as-received, $1^{\text {st }}$ pre-stretched and $2^{\text {nd }}$ pre-stretched billets. The compressive specimens are with the height and diameter with $15 \mathrm{~mm} \times 10 \mathrm{~mm}$. Tensile and compressive tests are carried out on a CMT6305-300KN electronic universal testing machine at room temperature. The strain rate was set at $10^{-3} \mathrm{~s}^{-1}$.

The microstructure is observed by optical microscopy and electron backscatter diffraction (EBSD). The EBSD test is conducted on ED-TD plane of the Mg specimens by a Zeiss EVO 50 SEM and the data were processed by INCA OXFORD crystal software.

\section{Results and Discussions}

Microstructure and (0002) pole figure of as-extruded AZ31 Mg alloys are shown in Figure 2. It can be seen that equiaxial grains distribute and there are no twins emerging in the microstructure. The grain size is about $15.5 \mu \mathrm{m}$. Besides, (0002) pole figure of $\mathrm{Mg}$ billet expresses a typical extruded texture and basal plane of grains are parallel to extrusion direction.

True strain vs stress curves of various pre-strained specimens during inverse tension and compression are shown in Figure 3. It can be seen that as-extruded Mg expresses a typical tensile curve; however, it shows a hollow during yield stage after pre-compression $3 \%$ process. Sarker et al. ${ }^{15}$ indicated that detwinning would be active during inverse tension on pre-compressed AM30 magnesium alloys. Detwinning behavior is a similar deformation mechanism which will result in tensile curves emerging depression. For pre-stretched $\mathrm{Mg}$ billets, all of the specimens express typical compressive curves. This indicates that pre-stretch process has no obvious effects on the deformation mechanism during compression.

Figure 4 shows the tensile/compressive yield strength (TYS/CYS) and peak strength (TPS/CPS) on various pre-strained specimens. TYS decreases from $132.3 \mathrm{MPa}$ to $97.6 \mathrm{MPa}$ after $1^{\text {st }}$ pre-compression comparing with asextruded specimens. However, it increases to $117.4 \mathrm{MPa}$ after $2^{\text {nd }}$ pre-compression $3 \%$ process which should be related to the strain hardening behaviors. For TPS, it increases from $323.3 \mathrm{MPa}$ to $345.2 \mathrm{MPa}$ and $341.1 \mathrm{MPa}$ after $1^{\text {st }}$ and $2^{\text {nd }}$ pre-compression, respectively. The peak strength after $1^{\text {st }}$ and $2^{\text {nd }}$ pre-compression $3 \%$ is almost consistent. Figure 4 (b) shows the compressive yield (CYS) and peak strength (CPS) on various pre-stretched specimens. CYS increases on both $1^{\text {st }}$ and $2^{\text {nd }}$ pre-stretched $\mathrm{Mg}$ alloys. Comparing with as-extruded samples, it increases from 108.2MPa to 137.3MPa and 145.5MPa. CPS decreases from 349.2MPa (as-extrusion) to $337.8 \mathrm{MPa}\left(1^{\text {st }} \mathrm{prs}\right)$ and $342.4 \mathrm{MPa}\left(2^{\text {nd }}\right.$ prs), respectively. The changes are relative smaller which is similar with TPS on pre-compressed specimens. This phenomenon indicates pre-strain deformation just has an 

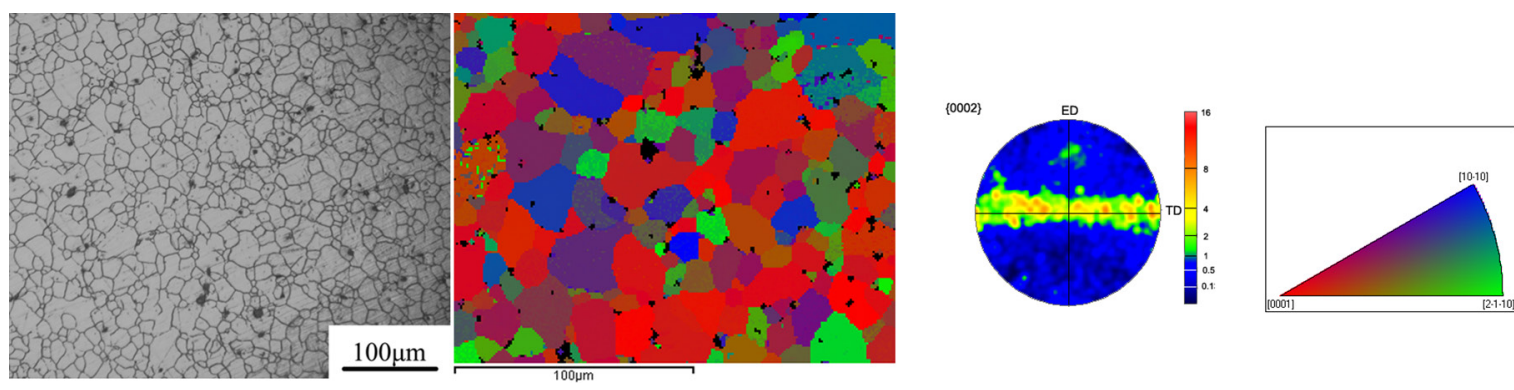

Figure 2. Microstructure and (0002) pole figure of as-extruded AZ31 magnesium alloy
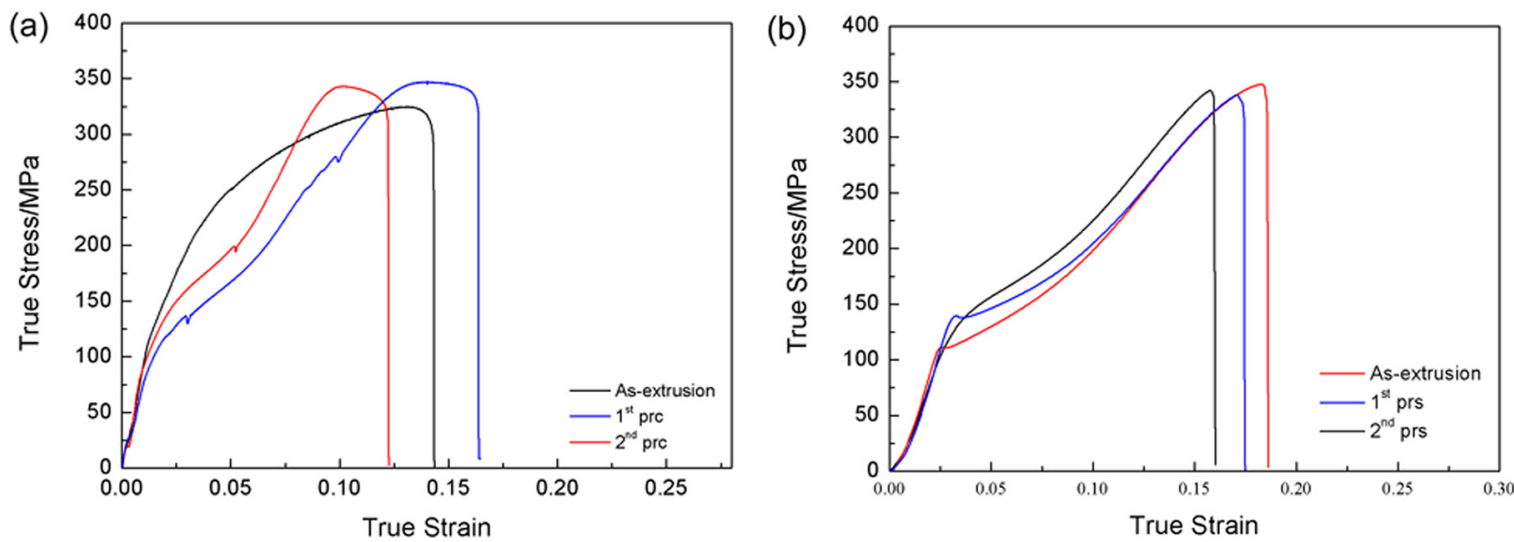

Figure 3. True strain vs stress curves of various pre-strain specimens: (a) tension, (b) compression

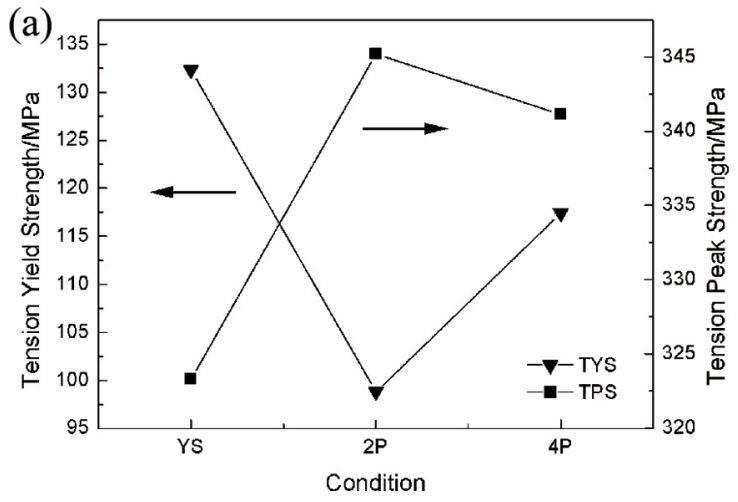

(b)

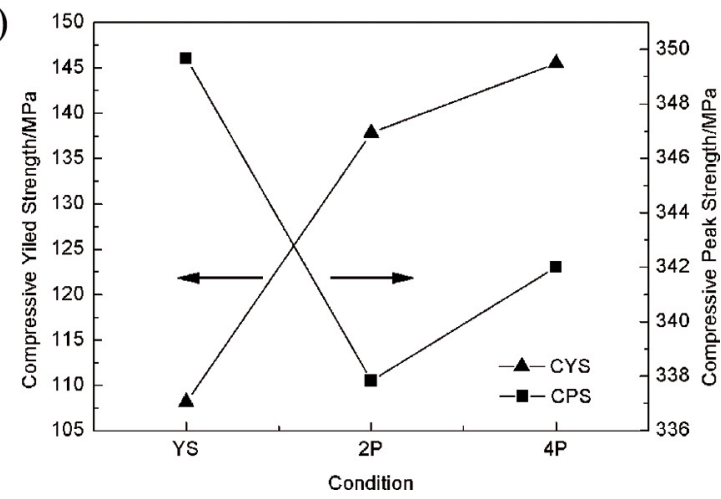

Figure 4. Tensile/compressive yield strength and peak strength on various pre-strained specimens

important effect on the yield stage. In order to make clear the evolution of mechanical properties, microstructures on various pre-strain deformations are observed.

Evolution of microstructures during $1^{\text {st }}$ and $2^{\text {nd }}$ precompression Mg specimens is shown in Figure 5. It can be seen that a large volume fraction of twins generates after pre-compression $3 \%$ and annealing at $200^{\circ} \mathrm{C}$ for $3 \mathrm{~h}$. The type of the twins can be recognized as $\{10-12\}$ tensile twins which leads to grains rotates from TD to ED about $86^{\circ}$.Thus, a ED// texture is generated, as shown in Figure 5 (e). The twins can be existed after annealing which is consistent with previous research. Xin et al. ${ }^{16}$ reported that the dislocations could be removed and $\{10-12\}$ twinning variants induced by pre-compression along TD on magnesium alloys would be kept after annealing at $200^{\circ} \mathrm{C}$ for $6 \mathrm{~h}$. However, the twins disappear after inverse tension 3\%, as shown in Figure 5 (b). As well known, $\{10-12\}$ twinning is a polar mechanism. It can be active only when the tensile load is parallel or compressive load is perpendicular to c-axis of grains ${ }^{17,18}$. However, Wu et al. ${ }^{14}$ and Sarker et al. ${ }^{15}$ reported that detwinning behaviors would happen when the inverse tensile load was carried out on compressed Mg samples. Due to detwinning, \{10-12\} tensile twins induced by pre-compression disappear after inverse tension $3 \%$. So detwinning dominates the yield stage during inverse tensile deformation on $1^{\text {st }}$ pre-compression specimens. While, the critical resolved shear stresses (CRSS) 


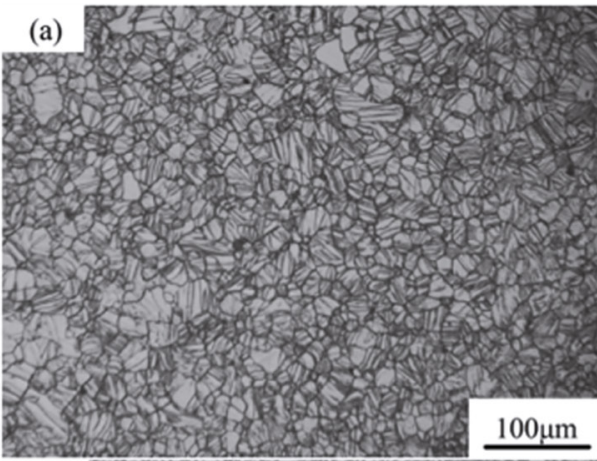

(c)

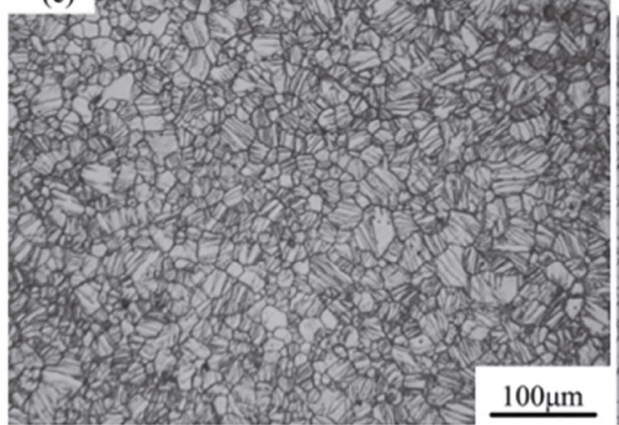

$100 \mu \mathrm{m}$

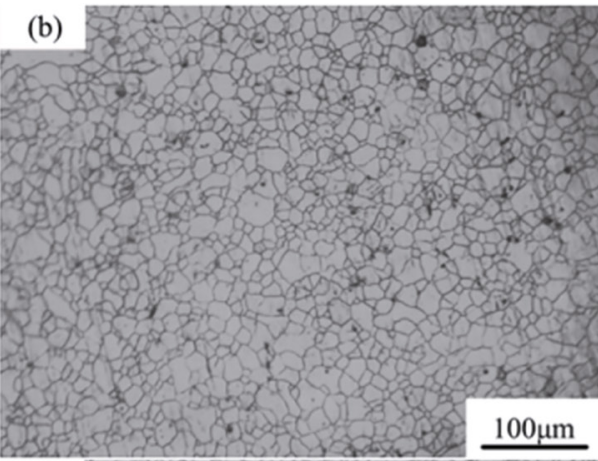

(d)

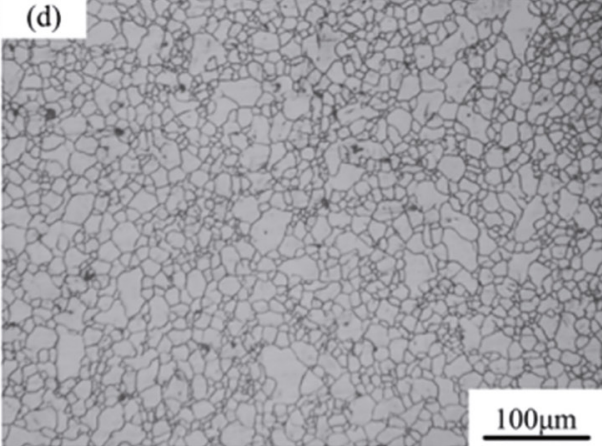

(e)
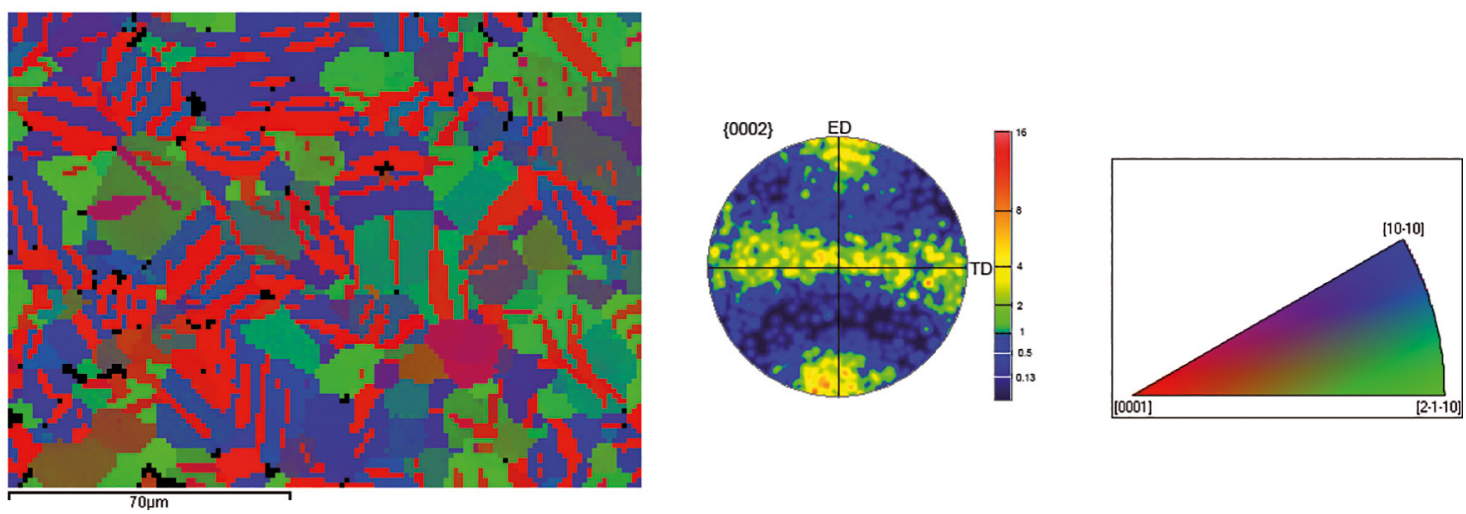

Figure 5. Evolution of microstructures during pre-compression on AZ31 Mg alloy billets: (a) 1st prc3\%, (b) 1st inverse tension 3\%, (c) 2nd pre 3\%, (d) tensile to fracture, (e) EBSD maps of 1 st prc3\% specimens.

of detwinning is much smaller than prismatic slips ${ }^{19}$. Thus, the yield strength decreases than as-extruded Mg billets.

During $2^{\text {nd }}$ pre-compression $3 \%,\{10-12\}$ tensile twins are generated again and detwinning also happens after inverse tension to fracture on $2^{\text {nd }}$ pre-compressed $\mathrm{Mg}$ specimens. Equiaxed grains distribute in the microstructure. While the grain size of $1^{\text {st }}$ inverse tension $3 \%$ and $2^{\text {nd }}$ inverse tension to fracture specimens are $14.5 \mu \mathrm{m}$ and $15.1 \mu \mathrm{m}$. This concludes that detwinning has little effect on evolution of grain size. Thus, cycling deformation like fatigue process of magnesium alloys can be regarded as a twinning-detwinning mechanism alternately dominates the deformation. Due to the rotation $86^{\circ}$ of grains induced by $\{10-12\}$ tensile twins, a softening effect are applied during inverse tensile deformation stage. So the fatigue life can be enhanced by pre-twinning. However, comparing microstructures of $1^{\text {st }}$ with $2^{\text {nd }}$ pre-compression $3 \%$ specimens, it seems that the volume fraction of twins decreases. Sheng et al..$^{20}$ reported that the c/a axial ratio would be decreased after tension for a smaller degree which led to the distance of tangential strain of $\{10-12\}$ twins increasing. And the resistance of twins would increase as well. So the volume fraction of $\{10-12\}$ tensile twins on inverse tension 3\% Mg specimens decreases during $2^{\text {nd }}$ pre-compression deformation. Due to the smaller amount of tensile twins, the softening effect is weakened at the same time. And the strain hardening will play a more important role than softening effect induced by twins as the cycling deformation continuing. From Figure 4 (a), TYS of $2^{\text {nd }}$ pre-compression is larger than $1^{\text {st }}$ prc samples, which may be related to this transformation. The strain hardening will be investigated in following parts. 
Figure 6 shows the evolution of microstructures during pre-stretch deformation. After $1^{\text {st }}$ pre-stretch $3 \%$ and annealing at $200^{\circ} \mathrm{C}$ for $2 \mathrm{~h}$, the grains are elongated with a size of $14.8 \mu \mathrm{m}$. It rotates from TD to ED about $10^{\circ}$ and still keeps a basal fiber texture. When $1^{\text {st }}$ compression $3 \%$ is conducted along ED, a large amount of $\{10-12\}$ twins are generated. So tensile twinning is still the dominate deformation mechanism. Then detwinning behavior happens and $\{10-$ $12\}$ tensile twins disappear during $2^{\text {nd }}$ pre-stretch $3 \%$. The grain size is about $15.7 \mu \mathrm{m}$ which keeps almost consistent with as-extruded and $1^{\text {st }}$ pre-stretch specimens. At last, $2^{\text {nd }}$ inverse compression is conducted and twins emerge again. However, comparing with microstructure of $1^{\text {st }}$ compressed specimens, the volume fraction of twins decreases obviously. This may be related to the drop of c/a axial ratio by prestretch. Due to the increasing distance of tangential strain of $\{10-12\}$ tensile twins, the amount of twins decreases. So the compressive yield strength improved and CYS is larger on $2^{\text {nd }}$ than $1^{\text {st }}$ pre-stretched $\mathrm{Mg}$ specimens. From the evolution of microstructures, it can state that the cycling deformation is dominated by twinning-detwinning behaviors. And the strain hardening and softening effect induced by twins play a competitive role during the deformation alternately. At first, the softening effects play an important role while the strain hardening plays much more important role as the deformation continuing. Based on previous analysis, it can be concluded that pre-compression does benefits on the cycling deformation than pre-stretch process due to softening effects induced by twins at first stage.

Figure 7 (a) indicates strain hardening rate $(\theta=d \sigma / d \varepsilon)$ vs flow stress $\left(\sigma-\sigma_{0.2}\right)$ of various pre-compressed specimens during inverse tension test. It can be seen hardening rate $(\theta)$ decreases linearly with stress on as-extruded $\mathrm{Mg}$ specimens. However, $\theta$ keeps the same trend at initial stage on $1^{\text {st }}$ and
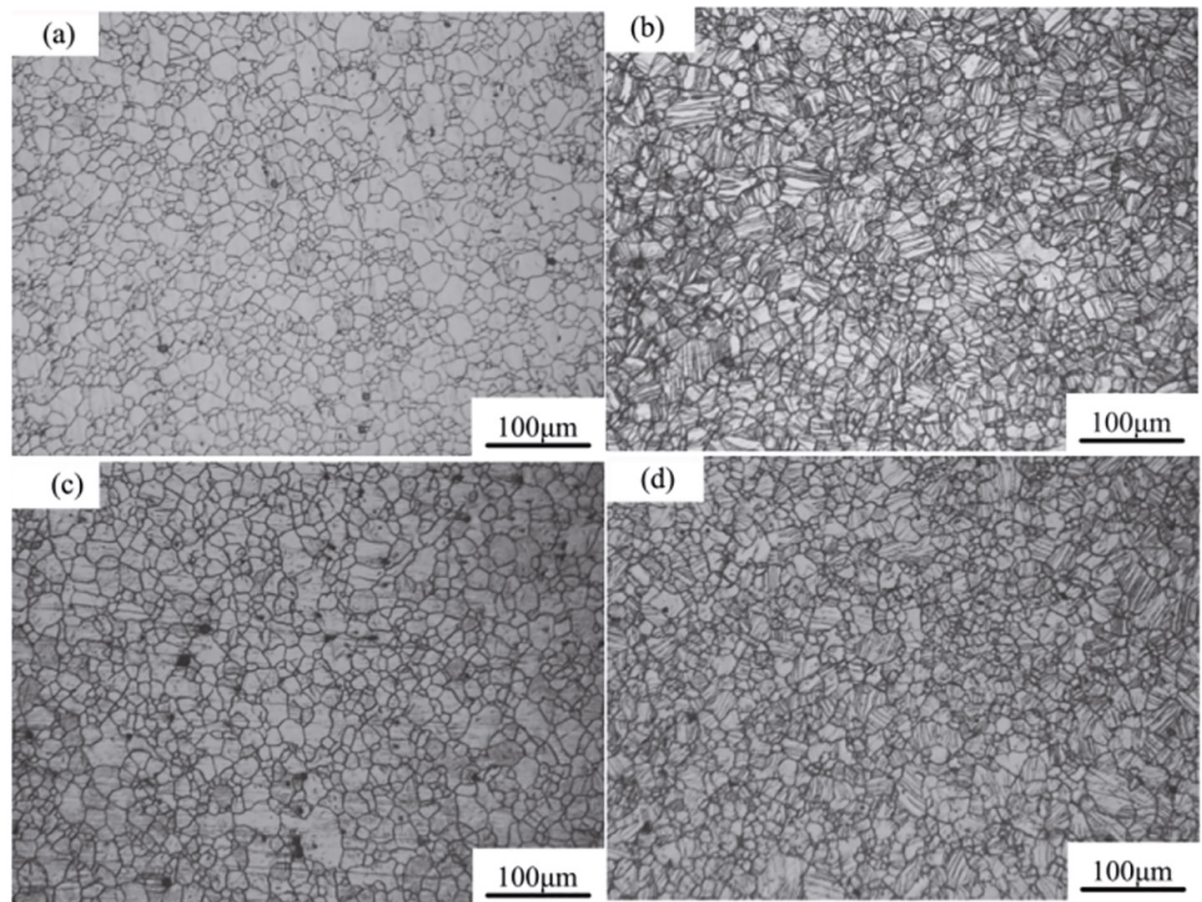

(e)
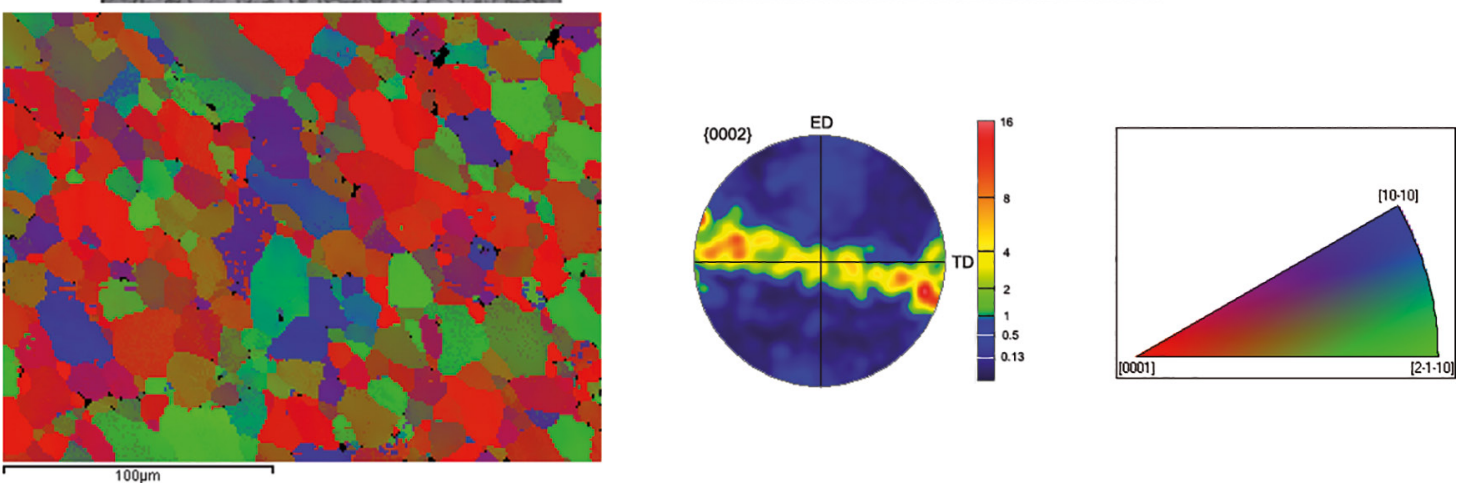

Figure 6. Evolution of microstructures during pre-stretch on AZ31 Mg alloy billets: (a) $1^{\text {st }}$ prs $3 \%$, (b) $1^{\text {st }}$ inverse compression $3 \%$, (c) $2^{\text {nd }}$ prs $3 \%$, (d) compression to fracture, (e) EBSD maps of $1^{\text {st }} \operatorname{prcs} \%$ specimens. 

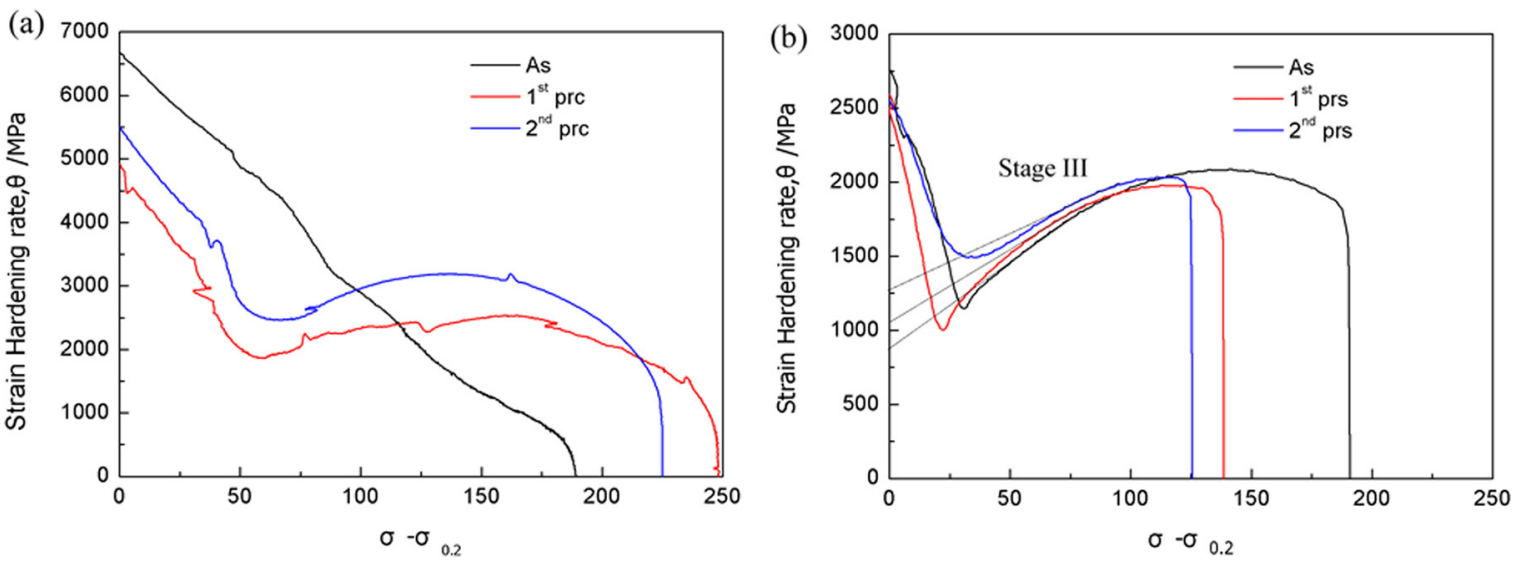

Figure 7. The strain hardening rate of various pre-strained $\mathrm{Mg}$ specimens: (a) tension, (b) compression.

$2^{\text {nd }}$ prc samples then increases as the stress increasing. This means an obvious strain hardening happens. After $1^{\text {st }}$ pre-compression $3 \%$ and annealing process, the twinning variants are kept in the microstructure. Besides, during inverse tension test, the dislocation slips will be active as the strain levels increasing. Thus, the reserved twinning lamellas will become barriers to prevent dislocation movement ${ }^{21}$. The interaction between twins and dislocation slips leads to the increase strain hardening at this stage. As the deformation continues, detwinning behavior happens. Detwinning is a process of the thickness and volume fraction of $\{10-12\}$ tensile twins reducing. So the volume fraction of $\{10-12\}$ twins decreases during inverse tensile deformation. The transformation can be observed in Figure 5 (b). And due to the decreasing amount of twinning lamellas, the strain hardening rate decreases at the same time in last stage. And $\theta$-value on $2^{\text {nd }}$ pre specimens is always higher than $1^{\text {st }}$ pre $\mathrm{Mg}$ specimens. It is mainly because the fraction of $\{10-$ 12 t twins during $2^{\text {nd }}$ pre-compression process reduces and the induced orientation softening effects are weakened, as shown in Figure 5(c). The hardening caused by dislocation contributes more functions during tension deformation which led to the higher $\theta$.

For inverse compression deformation, the hardening rate of stage III increases linearly with stress ${ }^{22}$ and the slop of stage III decreases after $1^{\text {st }}$ prs and $2^{\text {nd }}$ prs process, as shown in Figure 7 (b). The decreased slop indicates that pre-stretch has significant impact on the slop of stage III. From Figure 6 (b) and (d), it can be seen that $\{10-12\}$ tensile twins are the dominate deformation mechanism during the inverse compression yield stage. It has been reported that twinning does not only introduce additional barriers to dislocation glide, but also has a grain reorientation effect. Brown et al. ${ }^{23}$ suggested that the initial $\{10-12\}$ twins rotated grains to ED about $86^{\circ}$ which was a hard orientation during compression deformation. The hard orientation causes texture strengthening as well. So it can be concluded that texture strengthening is the major factor affecting the strain hardening of stage III. Besides, twinning lamellas are providing additional barriers to the accumulation of dislocations which enhances the strength effects. So as decreasing volume fraction of $\{10-12\}$ tensile twins, the hardening will be weakened and the slop decreases. In previous research, pre-stretch will drop c/a axis ratio and the activation of $\{10-12\}$ twinning is restrained $^{24}$. So the volume fraction of extension twins decreases after $1^{\text {st }}$ prs $3 \%$ deformation and the slop stage III decreases comparing with as-extruded samples. After $2^{\text {nd }}$ prs deformation, the amount of twins reduces persistent and the slop of stage III decreases more. On the other hand, the dislocation density is also one important role on the strain hardening. However, song et al. ${ }^{7}$ indicated that the accumulation of dislocations and dynamic recovery play minor roles on the strain hardening. So the weakening texture hardening induced by reduced twinning amount is responsible for the lower slop of stage III in $2^{\text {nd }}$ prs Mg specimens.

\section{Conclusions}

In order to investigate effect of pre-strain on the evolution of microstructure and strain hardening of magnesium alloys, pre-compression/pre-stretch and subsequent annealing are applied on AZ31 magnesium billets. Detwinning behavior happens during inverse tension on pre-compressed samples. After $2^{\text {nd }}$ pre-compression, the volume fraction of extension twins decreases. Due to the interaction of dislocation slips with twinning lamellas, the strain hardening rate $(\theta)$ increases. The orientation softening effects weakens as the amount of $\{10-$ $12\}$ twins decreases which lead to strain hardening induced by dislocation plays more impact. Thus, the strain hardening rate is higher in $2^{\text {nd }}$ than $1^{\text {st }}$ pre-compressed samples. However, extension twinning is sustained by pre-stretch process. The texture strengthening caused by $\{10-12\}$ extension twins weakens as the volume fraction of twins, so the slop of stage III in strain hardening rate reduces in $1^{\text {st }}$ and $2^{\text {nd }}$ pre-stretch Mg alloys. 


\section{Acknowledgements}

This work is supported by Shanxi Province Science Foundation for Youths (2016021063), National Natural Science Foundation of China (51404166, 51504162), National Natural Science Foundation of China (51375328) and (51405500), Preresearch Foundation (9140A17040114KG01242), Fundamental Research Funds by Taiyuan University of Technology (tyutrc201523a) and (2015QN011), Research Project Supported by Shanxi Scholarship council of China (2016036).

\section{References}

1. Zhang H, Huang GS, Fan JF, Roven HJ, Xu BS, Dong HB. Deep drawability and drawing behaviour of AZ31 alloy sheets with different initial texture. Journal of Alloys and Compounds. 2014;615:302-310.

2. Stanford N, Marceau RKW, Barnett MR. The effect of high yttrium solute concentration on the twinning behaviour of magnesium alloys. Acta Materialia. 2015;82:447-456.

3. Tahreen N, Chen DL, Nouri M, Li DY. Influence of aluminum content on twinning and texture development of cast Mg-Al- $\mathrm{Zn}$ alloy during compression. Journal of Alloys and Compounds. 2015;623:15-23.

4. Wang LF, Mostaed E, Cao XQ, Huang GS, Fabrizi A, Bonollo F, et al. Effects of texture and grain size on mechanical properties of AZ80 magnesium alloys at lower temperatures. Materials \& Design. 2016;89:1-8

5. Jiang J, Godfrey A, Liu Q. Influence of grain orientation on twinning during warm compression of wrought $\mathrm{Mg}-3 \mathrm{Al}-1 \mathrm{Zn}$. Materials Science and Technology. 2005;21(12):1417-1422.

6. Tsai MS, Chang CP. Grain size effect on deformation twinning in $\mathrm{Mg}-\mathrm{Al}-\mathrm{Zn}$ alloy. Materials Science and Technology. 2013;29(6):759-763.

7. Song B, Xin RL, Chen G, Zhang XY, Liu Q. Improving tensile and compressive properties of magnesium alloy plates by pre-cold rolling. Scripta Materialia. 2012;66(12):1061-1064.

8. Xu S, Liu TM, Chen HC, Miao ZH, Zhang Z, Zeng W. Reducing the tension-compression yield asymmetry in a hot-rolled Mg$3 \mathrm{Al}-1 \mathrm{Zn}$ alloy via multidirectional pre-compression. Materials Science and Engineering: A. 2013;565:96-101.

9. Lou C, Zhang XY, Ren Y. Improved strength and ductility of magnesium alloy below micro-twin lamellar structure. Materials Science and Engineering: A. 2014;614:1-5.

10. Ozaki J, Yosida M, Horibe S. The effect of pre-compressive strain on the fatigue life of the AZ31 magnesium alloy. Materials Science and Engineering: A. 2014;604:192-195.
11. Xin YC, Wang MY, Zeng Z, Huang GJ, Liu Q. Tailoring the texture of magnesium alloy by twinning deformation to improve the rolling capability. Scripta Materialia. 2011;64(10):986-989.

12. Zhang H, Huang GS, Wang LF, Li JH. Improved formability of Mg-3Al-1Zn alloy by pre-stretching and annealing. Scripta Materialia. 2012;67(5):495-498.

13. Sarker D, Friedman J, Chen DL. Influence of pre-deformation and subsequent annealing on strain hardening and anisotropy of AM30 magnesium alloy. Journal of Alloys and Compounds. 2014;611:341-350.

14. Wu W, An K. Understanding low-cycle fatigue life improvement mechanisms in a pre-twinned magnesium alloy. Journal of Alloys and Compounds. 2016;656:539-550.

15. Sarker D, Chen DL. Dependence of compressive deformation on pre-strain and loading direction in an extruded magnesium alloy: Texture, twinning and de-twinning. Materials Science and Engineering: A. 2014;596:134-144.

16. Xin YC, Wang MY, Zeng Z, Nie MG, Liu Q. Strengthening and toughening of magnesium alloy by $\{10-12\}$ extension twins. Scripta Materialia. 2012;66:25-28.

17. Hong SG, Park SH, Lee CS. Role of $\{10-12\}$ twinning characteristics in the deformation behavior of a polycrystalline magnesium alloy. Acta Materialia. 2010;58(18):5873-5885.

18. Zhang H, Liu Y, Fan JF, Roven HJ, Cheng WL, Xu BS, et al. Microstructure evolution and mechanical properties of twinned AZ31 alloy plates at lower elevated temperature. Journal of Alloys and Compounds. 2014;615:687-692.

19. Agnew SR, Duygulu Ö. Plastic anisotropy and the role of nonbasal slip in magnesium alloy AZ31B. International Journal of Plasticity. 2005;21(6):1161-1193.

20. Sheng GM, Zhang GT, Yan C. Research of Bauschinger Effect of AZ31 Magnesium Alloy. Rare Metal Materials and Engineering. 2011;40(4):616-619.

21. Wang BS, Xin RL, Huang GJ, Liu Q. Effect of crystal orientation on the mechanical properties and strain hardening behavior of magnesium alloy AZ31 during uniaxial compression. Materials Science and Engineering: A. 2012;534:588-593.

22. Jiang L, Jonas JJ, Luo AA, Sachdev AK, Godet S. Influence of $\{10$ $12\}$ extension twinning on the flow behavior of AZ31 Mg alloy. Materials Science and Engineering: A. 2007;445-446:302-309.

23. Brown DW, Agnew SR, Bourke MAM, Holden TM, Vogel $\mathrm{SC}$, Tomé CN. Internal strain and texture evolution during deformation twinning in magnesium. Materials Science and Engineering: A. 2005;399(1-2):1-12.

24. Wang LF, Huang GS, Quan Q, Bassani P, Mostaed E, Vedani M, et al. The effect of twinning and detwinning on the mechanical property of AZ31 extruded magnesium alloy during strain-path changes. Materials \& Design. 2014;63:177-184. 